\title{
Sustaining Negotiated QoS in Connection Admission Control for ATM Networks Using Fuzzy Logic Techniques
}

\author{
Olufade F. Williams Onifade. \\ University of Ibadan, Ibadan, \\ Nigeria
}

fadowilly@yahoo.com

\author{
G. A. Aderounmu, \\ Obafemi Awolowo University, \\ Ile-Ife, Nigeria
}

gaderoun@oauife.edu.ng

\author{
Oluwasikemi Tayo \\ Bowen University, Iwo, Nigeria
}

silverkid2be@yahoo.com

\begin{abstract}
The objective of connection admission control (CAC) is to keep the network load moderate to achieve a performance objective associated with Quality of Service (QoS). Cell Loss Ratio (CLR), a key QoS parameter in ATM networks, is essential for proper network resources dimensioning, congestion control, bandwidth allocation and routing.

In this research, we employed fuzzy logic technique in Statistical Connection Admission Control (S-CAC) - a CAC employing multiplexing of the bandwidth between the peak cell rate and the sustained (average) cell rate. The fuzzy technique consists of an input stage, a processing stage, and an output stage. We defined the rules with "max-min" inference method in which the output membership function is given the truth value generated by the premise. The results was defuzzified to a crisp value using the "centroid" method which favors the rule with the output of the greatest area, and the result thereafter charted to compare it operation.
\end{abstract}

Keywords: ATM, Fuzzy Logic, Connection Admission Control (CAC), B-ISDN, QoS.

\section{Introduction}

The major objective of ATM is to integrate real-time information such as voice and video with non-real-time computer data, within the same transmission and switching medium ("TechArena Community”, 2007). Data requires very low Bit Error Rate (BER) but can tolerate large propaga-

Material published as part of this publication, either on-line or in print, is copyrighted by the Informing Science Institute. Permission to make digital or paper copy of part or all of these works for personal or classroom use is granted without fee provided that the copies are not made or distributed for profit or commercial advantage AND that copies 1) bear this notice in full and 2) give the full citation on the first page. It is permissible to abstract these works so long as credit is given. To copy in all other cases or to republish or to post on a server or to redistribute to lists requires specific permission and payment of a fee. Contact Publisher@InformingScience.org to request redistribution permission. tion delays (seconds) (Valcourt, 1997). Voice and video require small propagation delays (milliseconds) but can tolerate some errors or small losses of information.

The objectives of ATM traffic management are to deliver Quality of Service (QoS) guarantee for the multimedia applications and provide overall optimization of network resources (Esaki, Iwa- 
mura, Kodama, \& Fukuda, 1994). The control of ATM traffic is complicated due to ATM's high link speed and small cell size, the diverse service requirements of ATM applications, and the diverse characteristics of ATM traffic (Suda, 1998). The environment also has a significant impact on the choice of control mechanism, either local or wide area.

Connection Admission Control (CAC) is a procedure responsible for determining whether a connection request is admitted or denied. The procedure is based on resource allocation schemes applied to each link and switching unit (Esaki et al., 1994). Admission control decision is made using a traffic descriptor that specifies traffic characteristics alongside the QoS requirements. These traffic characteristics include: Peak Cell Rate (PCR); Sustainable Cell Rate (SCR); and Maximum Burst Size (MBS).

The statistical CAC takes advantage of the variable bit rate bursty nature of traffic with the hope that not all sources will need their peak rate at the same time thus balancing the peaks and valleys of the bit rates (Esaki et al., 1994). With this, allocation is made on the network which increases network utilization leading to network efficiency. Statistical gain can also be significant.

Fuzzy logic is multi-valued, dealing in degrees of membership or truth within the set (Kaehler, 1998; Kosko, 2003). Fuzzy logic $\mu_{\mathrm{s}}(\mathrm{x})$ describes the membership function of $\mathrm{S}$, or the degree to which $\mathrm{x}$ is a member of the set $\mathrm{S}$, this is known as the degree of truth.

$$
\mu_{s}(x)=\left\{\begin{array}{l}
1, \text { if } x \text { is totally } \epsilon S \\
0, \text { if } x \text { is not } \epsilon S \\
0<\mu_{s}(x)<1, \text { if } x \text { is partially } \in S
\end{array}\right.
$$

With fuzzy logic, this transition at the borders of sets is gradual, thus for the allowance for membership in both sets (Kaehler, 1998).

The fuzzy logic analysis and control method is, therefore:

- Receiving one of or a large number of measurements or other assessment of conditions existing in the control system.

- Processing all these inputs according to human based, fuzzy "If-Then" rules, which can be expressed in plain language words, in combination with traditional non-fuzzy processing.

- Averaging and weighting the resulting outputs from all the individual rules into one single output decision or signal which decides what to do or tells the controlled system what to do.

The output signal eventually arrived at is a precise appearing, defuzzified, "crisp" value as shown in Figure 1.

$\left.\begin{array}{l|l|l}\multicolumn{1}{l|}{\begin{array}{l}\text { Input } \\ \text { Measurement or } \\ \text { assessment of } \\ \text { Determine action } \\ \text { to be taken } \\ \text { based on human conditions. } \\ \text { determined fuzzy } \\ \begin{array}{l}\text { Examples: } \\ \text { temperature, } \\ \text { market data, } \\ \text { economic data. }\end{array}\end{array}} & \begin{array}{l}\text { "If-Then" rules } \\ \text { combined with } \\ \text { non-fuzzy rules. }\end{array}\end{array}\right)$

Figure 1: The Fuzzy Logic Control-Analysis Method 


\section{Background Study}

For ATM networks to integrate all types of data and multimedia user traffic, CAC functions must provide guaranteed, or at least differentiated, quality of service levels. This must occur at the packet level to meet rate and delay specifications, and also occur at the connection level to give differentiated access to shared resources (Valcourt, 1997).

Much of the existing work on CAC specifies the QoS parameters as fixed values (e.g., traffic with peak $10 \mathrm{Mbps}$, and deadline 30 milliseconds) and does not exploit the dynamic fluctuations in resource availability (Esaki et al., 1994; Tian, 1998). A connection can be viewed as a contract between an application and the connection management system. A real-time connection is additionally characterized by stringent deadline constraints imposed on its packet delivery time (Devalla et. al, 1999).

Several improvements have been made on traditional CAC. Once a connection is admitted, the traditional CAC provides a constant QoS to the connection throughout its lifetime. Thus, the traditional approach uses a simplistic QoS specification model and the consequent resource management suffers from many shortcomings that directly affect the applications using it. Specifically, this model is restrictive in that a fixed QoS model is not suitable for many applications that may accept admission at a lower QoS. For example, a video-on-demand application may be willing to accept a lower QoS (in terms of lesser bandwidth, jitter, etc.) to send video frames of poorer quality rather than send no frame at all (Aderounmu, Ogwu, \& Onifade, 2004; Devalla et al., 1999).

The static nature of the model is very insensitive to the dynamic changes in the QoS negotiated; consequently, the traditional CAC is very ineffective in terms of number of connection requests admitted, as it neither exploits the dynamism of the network nor the flexibility in QoS suitable to applications (Aderounmu et al., 2004). This also leads to a gross under-utilization of network resources.

The conceptual vision for the development of ATM networks is such that, it will accommodate different applications with varying characteristics and QoS, transmitting these applications on the same channel whilst sustaining QoS for each application is a serious task.

Statistical CAC multiplexes the excess available bandwidth of an application for another application with the hope that the first application would not exhaust the space eventually. This is one of the limitations of this approach, for bursty traffic that generates cells at peak rates and generates lower rates almost immediately, the following problems suffices:

- Buffer overflow occurs on multiplexed channel as a result of network congestion thereby resulting in the loss data packets, which grossly affects the QoS of the transmitting traffic (Aderounmu et al., 2004).

- Another problem is when an ATM terminal requests connection admission and supplies the CAC with only a limited amount of information concerning its bandwidth requirements. The absence of detailed information in the operation of CAC implies that calls which could be supported or otherwise refused.

Several attempts were made to improve on the above drawbacks, but the complex nature of statistical multiplexing coupled with diverse numbers of services accommodated on the network has rubbished them. Consequently, we employ fuzzy logic principles with the mode of operations and implementation taking into cognizance the following properties/attributes of fuzzy logic:

- Users do not have to specify their traffic parameters precisely from the call establishment and the output control is a smooth control function despite a wide range of input variations. 
- Using the user-defined rules, the control system can be modified easily by changing or including the appropriate rules to affect the change.

- Fuzzy logic is conceptually easy to understand. The mathematical concepts behind fuzzy reasoning are very simple. What makes fuzzy nice is the "naturalness" of its approach and not its far-reaching complexity.

- Fuzzy logic is flexible. With any given system, it's easy to manipulate it or put more functionality on top of it without starting again from scratch.

- Fuzzy logic is based on natural language. The basis for fuzzy logic was based on human communication. This observation underpins many of the other statements about fuzzy logic.

A demonstration of the max-min inference and centroid defuzzification for a system with input variables "x", "y", and "z" and an output variable "n" is given in Figure 2. Note that "mu" is standard fuzzy-logic nomenclature for "truth value":

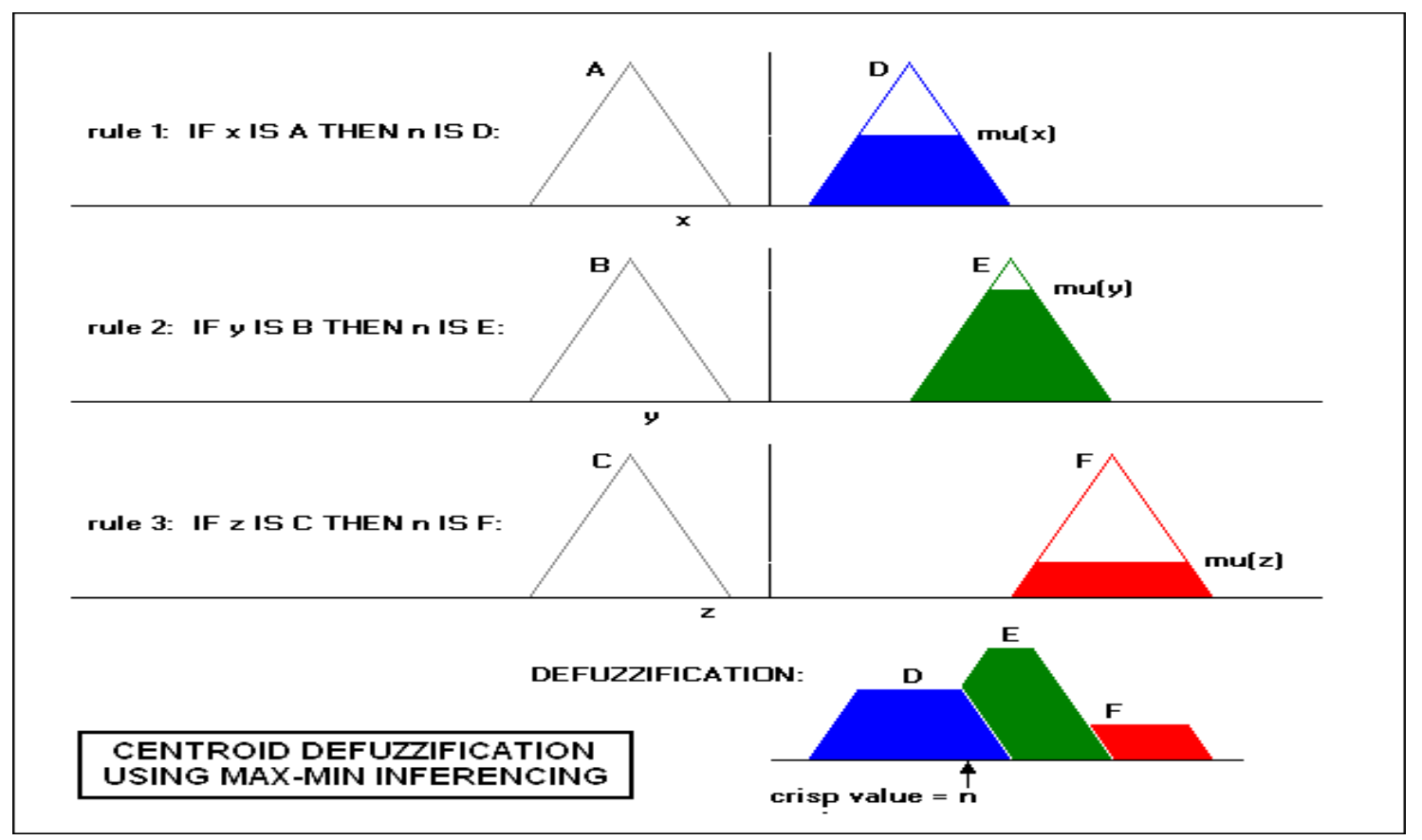

Figure 2: Centroid Defuzzification Employing Max-Min Inference (Kaehler, 1998)

\section{Methodology}

The objective of this approach is to control network congestion and the number of cell loss in ATM network. To be able to achieve this, calls that pose requests to transmit on the network have to be monitored and made to adhere to the transmitting policies already established. This involves ensuring that the available bandwidth is able to handle the Peak Cell Rate (PCR), Sustainable Cell Rate (SCR), Maximum Burst Size (MBS) of each individual connection so as to guarantee the connection's Quality of Service (QoS) throughout the course of transmission. The response or result expected is reduced network congestion as well as lower cell loss and should congestion arise, connections are dynamically assigned priorities to indicate their level of importance when cells are to be discarded.

We defined the following input variables to be employed in the approach: 
- Peak Cell Rate: This is the maximum allowable rate at which cells can be transported along a connection in the network (Suda, 1998). It is a determining factor in how often cells are sent in relation to time in an effort to minimize jitter. When coupled with Cell Delay Variation Tolerance (CDVT), it indicates how much jitter is allowable.

- Sustainable Cell Rate: This is the calculation of the average allowable, long term call transfer rate on a specific connection.

- Maximum Burst Size: This is the maximum allowable burst size of cells that can be transferred contiguously on a particular connection (Aderounmu, et. al, 2004).

- Bandwidth: This is the range of frequencies transmitted without being strongly attenuated The bandwidth is a physical property of the transmission medium and usually depends on the construction, thickness and length of the medium (Aderounmu, et. al, 2004).

- Cell Loss Probability (CLP): This parameter determines the priority of the cell through the network.

The above mentioned parameters formed the basis for the design of the CAC scheme, while the application of fuzzy logic was described by four main components:

1. The "rule-base" holds the knowledge, in the form of a set of rules, of how best to control the system.

2. The inference mechanism evaluates which control rules are relevant at the current time and then decides what the input to the system should be.

3. The fuzzification interface simply modifies the inputs so that they can be interpreted and compared to the rules in the rule-base.

4. The defuzzification interface converts the conclusions reached by the inference mechanism into the inputs to the system.

It was assumed that the bandwidth size is fixed. It is also assumed that the size of the packet is fixed. We also considered two traffic types: Constant Bit Rate traffic and Variable Bit Rate traffic.

\section{Performance Analysis \& Results Discussions}

We employed the Fuzzy Logic Toolbox to develop the Fuzzy Inference System (FIS) where the membership functions, rule base amongst other things were created. The inference system was divided into four parts with two inputs and one output each for each part. This is to maintain inherent simplicity. The parts include the:

- The Bandwidth and Peak Cell Rate Rule Base

- The Bandwidth and Sustainable Cell Rate Rule Base

- The Bandwidth and Maximum Burst Size Rule Base

- The Bandwidth and Cell Loss Probability Rule Base

With the above, the FIS was able to generate a sequence of inputs and outputs for each part based on the rule base developed and the resulting output charted to present a graphical representation.

I. Bandwidth and Peak Cell Rate

In our model, we based the relation between the bandwidth, PCR and the call status the following conditions. 
- The call is accepted if the PCR is low or average and BW is high

- The call is rejected if both the PCR and BW are high

- The call is rejected if the PCR is high or average and the BW is high

- The call is accepted if the PCR is low and the BW is average

- The call is rejected if the PCR is average or high and the BW is low

- The call is accepted when the BW is low only if the PCR is lower

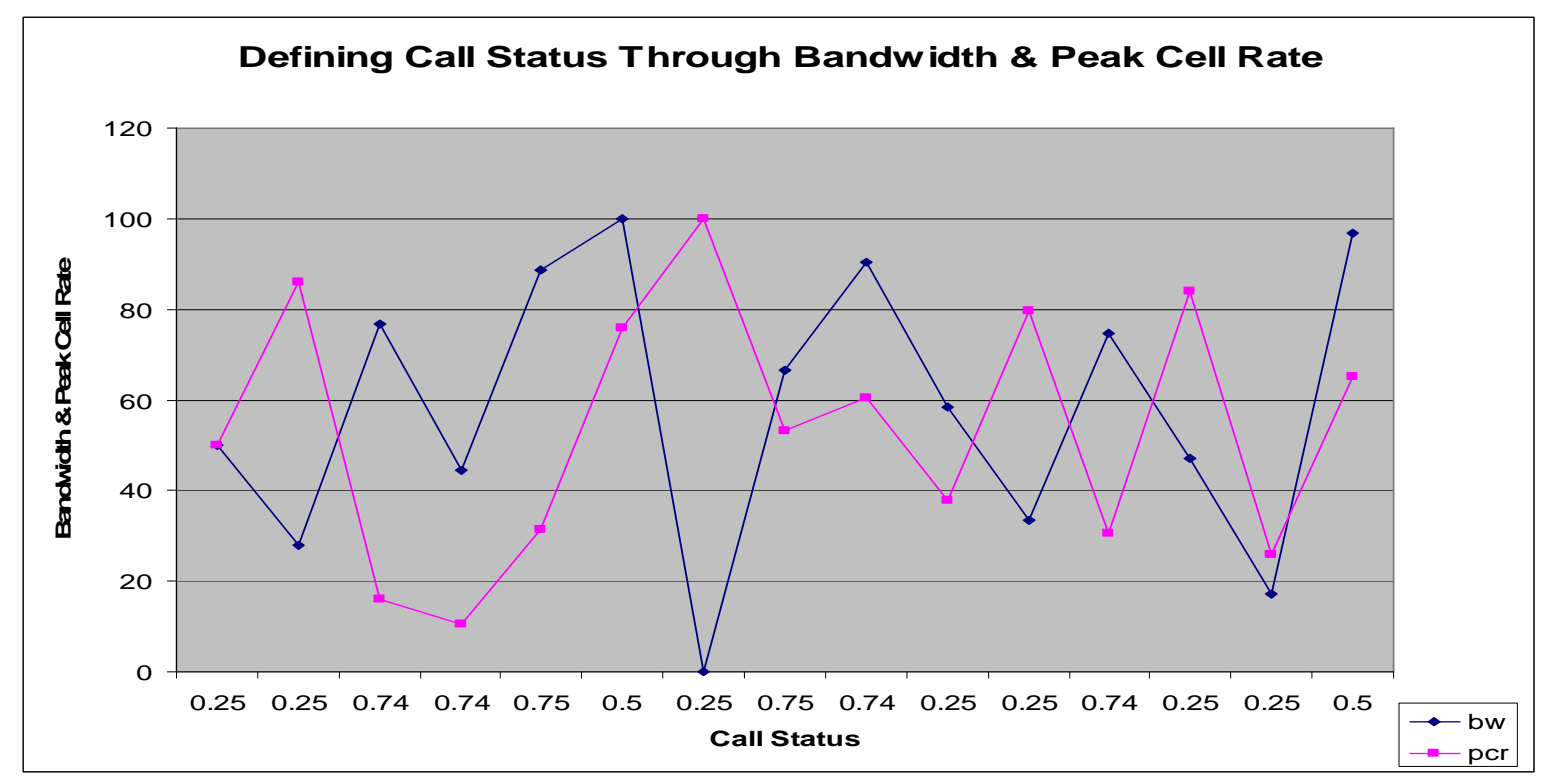

Figure 3: Evaluation of Bandwidth and Peak Cell Rate

In Figure 3, the decision on whether to admit or reject a call is dependent of the values of the BW and PCR at the time of request. A call is accepted within the range (0.5-1.0) and rejected within the range (0-0.49). If the bandwidth is high (i.e. 65-100 on a scale of $\mathbf{0 - 1 0 0}$ ), then there are chances that the call would be accepted. The call is only accepted if the PCR is average (35-64) or low (0-34) compared to the high bandwidth and rejected when both the BW and PCR are high. This means that the channel cannot accommodate the call should it reach its peak level.

In the situation whereby the bandwidth size is average (35-64), only calls having their PCR lower than the average are considered acceptable unto the channel. PCRs that are high or on the average are rejected to avoid network congestions. Should the bandwidth be low (0-34), then only calls with PCRs that are lower than the bandwidth will be accepted.

The overall concern is to avoid network congestion which ultimately results to reduced QoS for the calls transmitted. To avoid this, calls that have PCRs higher than the available bandwidth should be rejected. The above presents a better utilization of the network resources depicted by drastic reduction in the contention for available resources. With a true representation of a bursty environment in the simulation scenario, the new implementation was able to adjust to the "on and off" nature of the traffic pattern.

\section{Bandwidth and Sustainable Cell Rate}

Ideally, in a network environment, the SCR is always less than the PCR. With this, the available bandwidth must still be able to accommodate the call with the SCR value. The scale of the SCR for this model is the same with the PCR (i.e. 0-100). When the available bandwidth is high, then 
the call with a low or average SCR would be accepted on the network but a high SCR would be rejected. This is because, there should be enough bandwidth space should the call become bursty, which could not be predicted during the admittance stage.

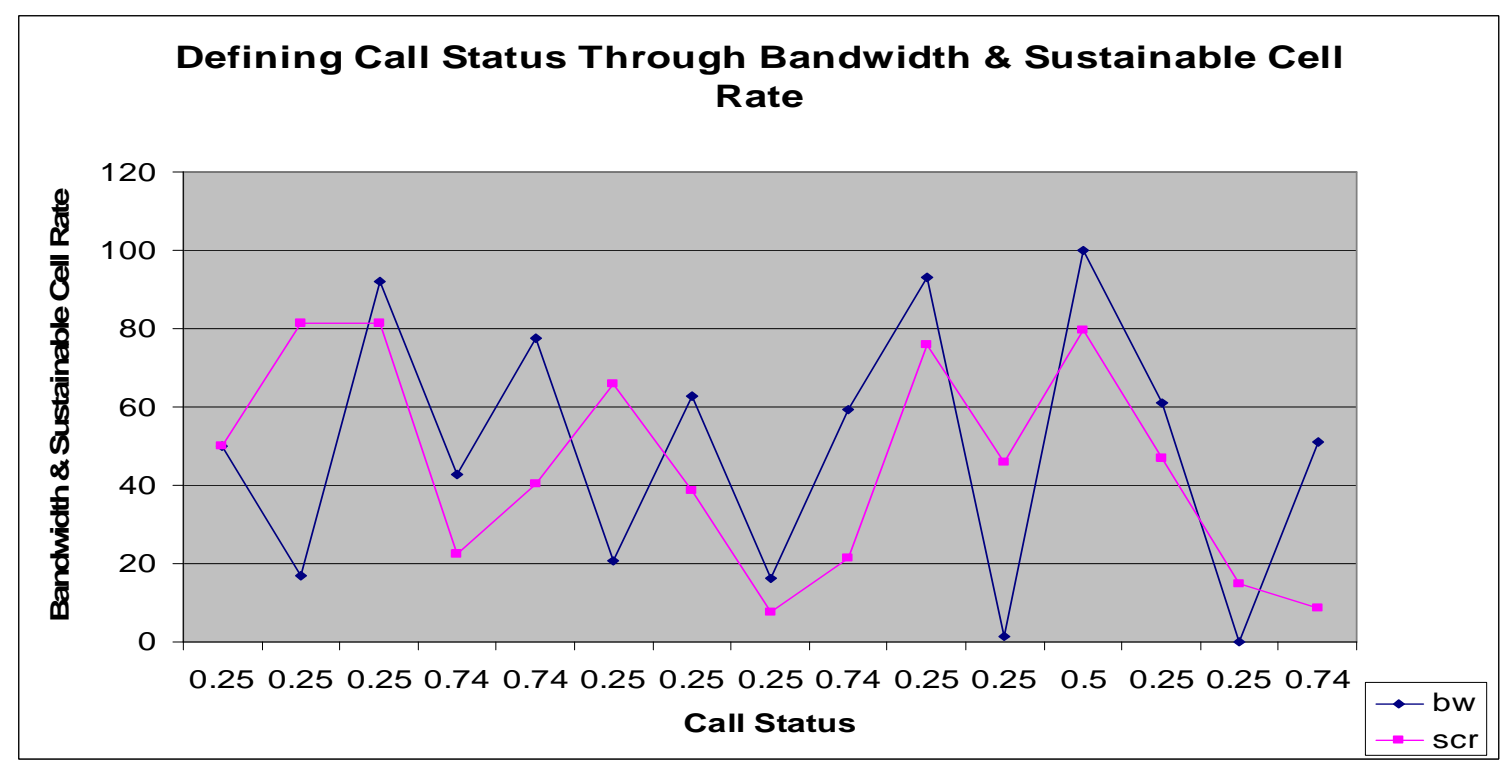

Figure 4: Evaluation of Bandwidth and Sustainable Cell Rate

This singular factor has derailed several attempts on the implementation of CAC. With this research, only calls that have a low SCR would be accepted on the network when the bandwidth is average and when the bandwidth is low (this is based on our research considerations and assumptions), and then the SCR has to be lower to avoid network congestion. The simulated result as shown in Figure 4 pinpoint that with the above consideration, unsolicited bursts which usually result into network/traffic congestion were properly accommodated. This is sequel to the fact that, admittance processes was properly guided by taking into consideration the probability of "admitted" calls becoming bursty during the cause of transmission.

\section{Bandwidth and Maximum Burst Size}

In a situation whereby a call will require more bandwidth during transmission outside the hitherto negotiated parameters and QoS, it becomes expedient that the extra space be accommodated by the channel to avoid loss of data packets or video packets in real-time transmissions. To ensure this, the size of the MBS must be dynamically adjusted to be lower than the available bandwidth to avoid such losses. This was achieved/enforced through the definition of call acceptance if and only if the PCR is average (35-64) or low (0-34) compared to the available bandwidth.

The MBS is usually greater than the SCR but less than the PCR. The research assumption is that, call is admitted when there is a high bandwidth if only the size of the MBS is either average (3564) or low (0-34) as depicted in Figure 5, thus leaving room for unprepared need for extra transmitting space. The above consideration of average size is based on our research finding while trying to simulate the expected throughput with available bandwidth. This further assists in determining the admittance or otherwise of calls.

At the point where the bandwidth is on the average level, the MBS has to be low for calls to be accepted. So also when the bandwidth is low, then the MBS has to be lower than the bandwidth for calls to be accepted on the network. Our scheme not only monitors this, but also ensures strict compliance to the hither to negotiated QoS as much as possible. With this, we are able to create a balance in the effect of burst which is cell loss and the overall admitted numbers of calls. 


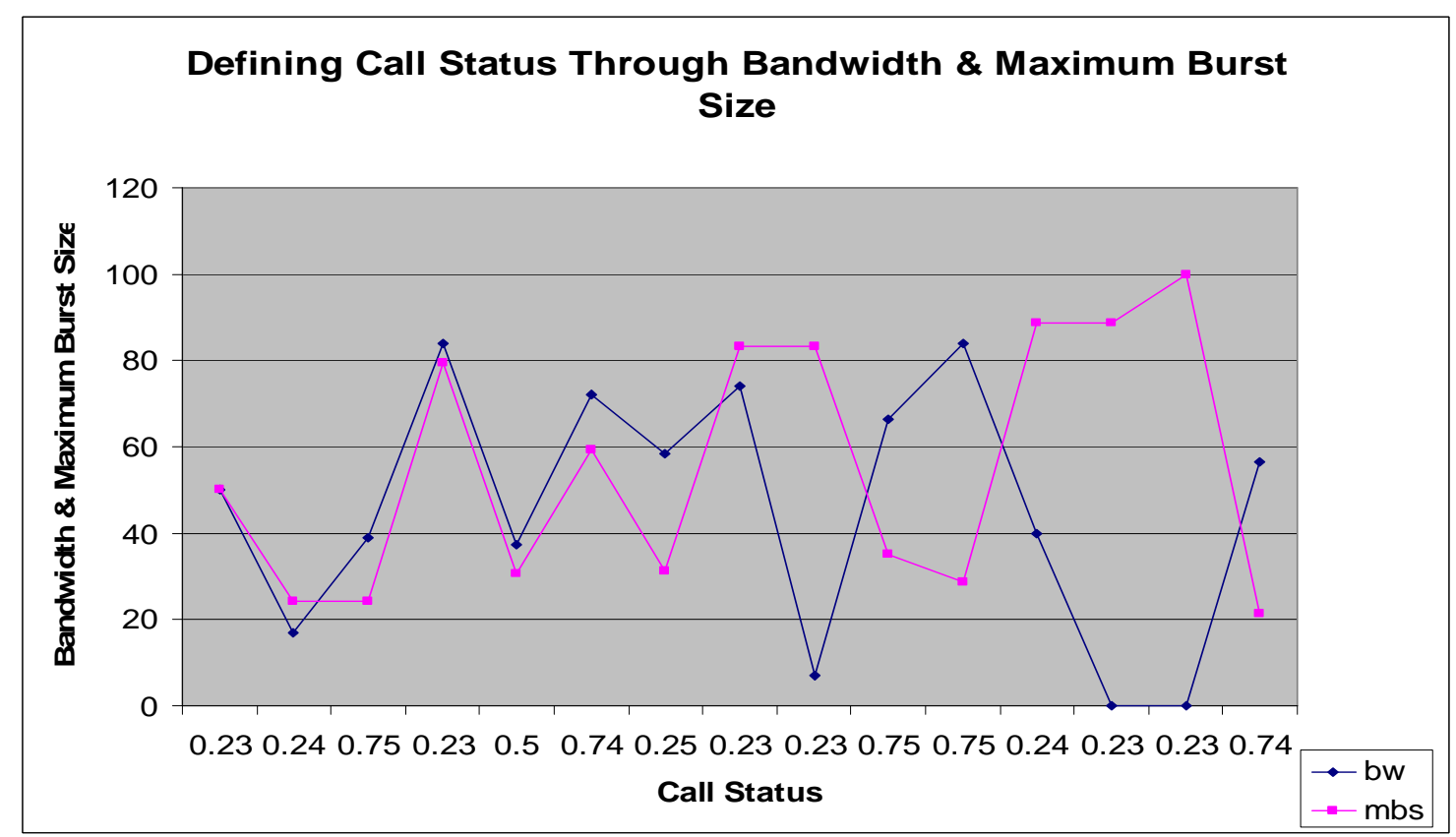

Figure 5: Evaluation of Bandwidth and Maximum Burst Size

IV. Bandwidth and Cell Loss Probability

There are situations whereby network congestion may occur; here calls are assigned cell loss probability to indicate the call that can be subject to packet loss through discarding. Here the calls to be discarded are based on the following. If the bandwidth is high and the CLP is either 0 or 1, the call is maintained on the channel. On the other hand, if the bandwidth is average, then the call is still maintained depending on if it has a CLP of either 0 or 1 . However, in a situation where the bandwidth is low then, the expectation is that only the call with CLP of 1 is accepted while the call with CLP of 0 is discarded. This is reflected in Figure 6, where the bandwidth and cell loss probability was charted against the call status.

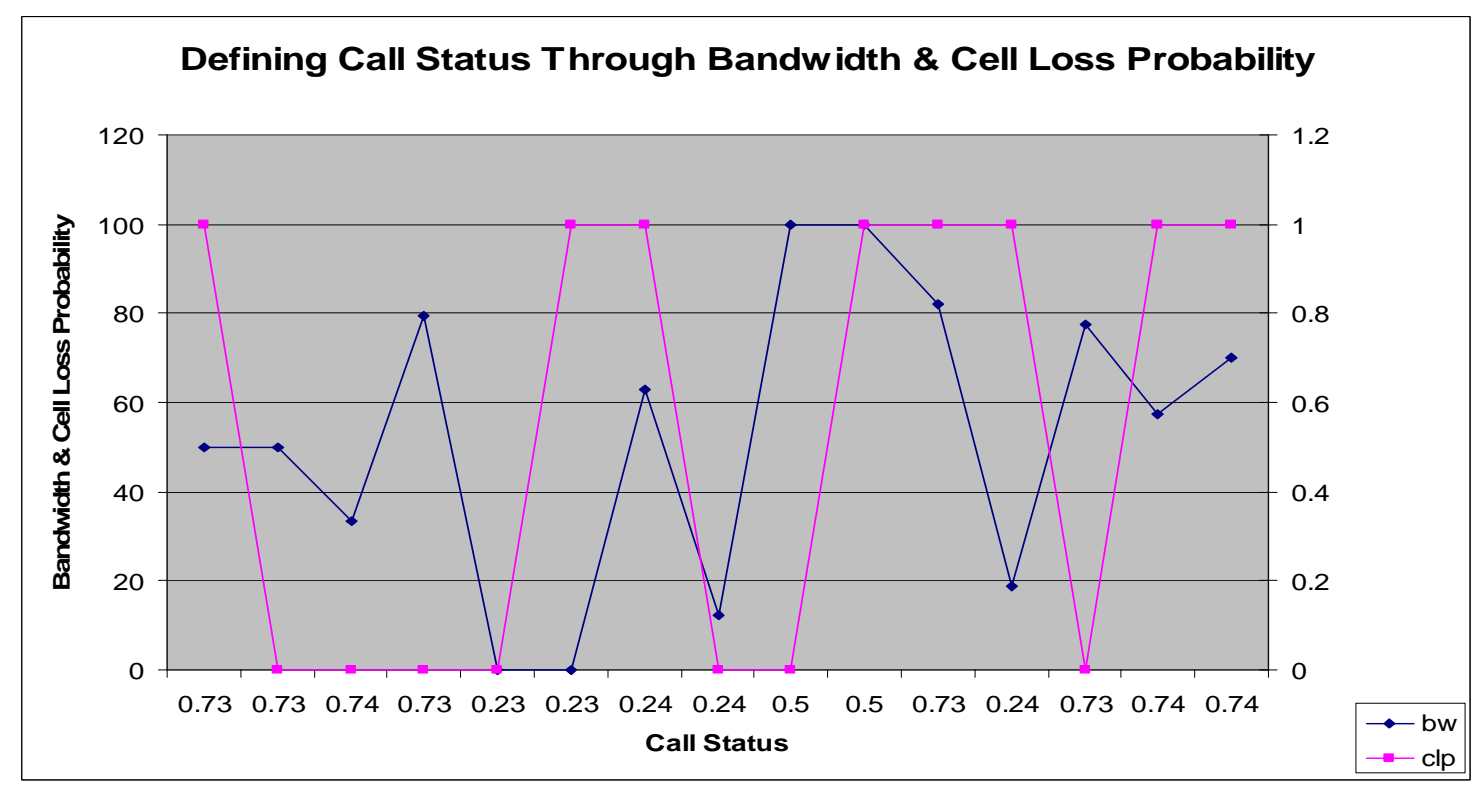

Figure 6: Evaluation of Bandwidth and Cell Loss Probability 


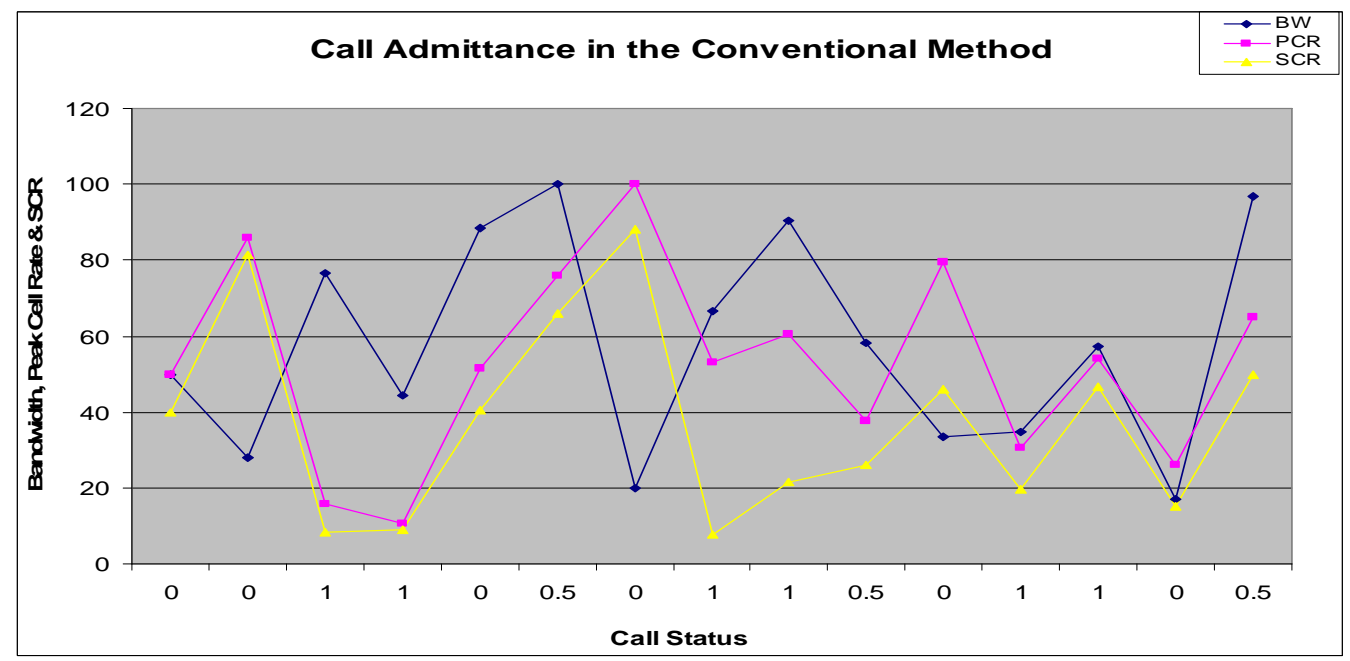

Figure 7: Evaluating conventional statistical CAC

\section{Comparative Analysis}

Figure 7 is the result of simulating the conventional statistical CAC using the same variables/parameters. It is quite obvious that transmission operation continues as long as there is no burst. Whenever the contrary situation occurs, i.e. a particular call becomes bursty; there would be a problem of accommodating this extra space because the available bandwidth is not enough. This is clearly evident in Figure 7 where the utilization depict close to total consumption of available bandwidth. If this situation persists, there will be network congestion and subsequent packet loss.

Figure 7 shows that calls are only accepted (i.e. $0.5 \&$ 1) when the available bandwidth is higher than either the PCR or the SCR and calls are rejected (i.e. 0) when the available bandwidth is lower than the PCR and SCR. It can also be deduced that the SCR is always lower than the PCR for each call.

With Figure 7, we are enabled to present analytical reports. It can be deduced that calls are usually rejected when the available bandwidth is not large enough to accommodate their traffic parameters which include the PCR, SCR, MBS, and CLP. The decision though on whether to accept or reject the call is going to be based the defuzzification of all the different rule bases of the inference system. This means that the conditions for the PCR, SCR and MBS would be evaluated simultaneously before a call can be admitted or rejected which allows for better determination of call acceptance/rejection pattern while the CLP conditions would be evaluated when there is network congestion and the appropriate decision taken thereafter. This presents a greater improvement on the method of admission in statistical multiplexing CAC where congestion resulting into loss results from the frequent bursty traffic.

On another view, if a call is rejected on its PCR basis, it can still stand a chance of acceptance if the call's SCR or MBS fall under the acceptance range while a call that was accepted on its MBS or SCR range stands a chance of being rejected if its PCR range is rejected by the system. Ideally, the PCR has the highest value among the input parameters (PCR, SCR, MBS) for a particular call so the chances that a call can be accepted or rejected has a major influence from the PCR value.

The conventional method is concerned with admitting calls based on their PCR and SCR only. This approach does not give consideration for bursty traffics where the needed bandwidth varies during transmission. So in situation where there is available bandwidth to transmit a call initially based on its SCR resulting into less space, should it become bursty, then there is high potential 
for network congestion. This problem was avoided in the fuzzy logic approach where calls admittance was based on dynamic calculation and the knowledge of the PCRs, SCRs, and MBSs. The simultaneous consideration of these factors enables better and more robust inference, thereby improving the overall performance of this new scheme when compared to the conventional method.

\section{Conclusion}

The research work has developed a fuzzy based approach to monitor/determine the admittance of calls into the network alongside with negotiated QoS. Calls are admitted based on their Peak Cell Rates, Sustainable Cell Rates and Maximum Burst Sizes. This implies that bursty traffic which could not have been determined at admittance point were adequately contained/managed, thus reducing the occurrence of network congestion and ultimately sustaining the QoS on the network.

The above was achieved by a "weighted" decision based on difficult condition in the rule base which first need be evaluated.

The result was a more robust approach, capable of sustaining, determining and managing an ATM networks by guaranteeing user-negotiated QoS at the point of admission, reduction in cell loss rate if not eliminating it, and more importantly, providing a platform for improved mode of utilizing the meager network resources.

\section{References}

Aderounmu, G. A, Ogwu, F. J., \& Onifade, O. F. W. (2004). A dynamic traffic shaper technique for a scalable QoS in ATM networks. International Conference on Computing, Communications and Control Technologies (ICCCCT'04), Aug 14-17, 2004 - Austin, Texas, USA, pp 332-337

Beard, C. C., \& Frost, V. S. (1998). Dynamic agent-based prioritized connection admission for stresses networks. Information \& Telecommunication Technology Center, Department of Electrical Engineering \& Computer Science, The University of Kansas, Lawrence, KS 66045, 1998.

Devalla, B., Sahoo, A., Guan, Y., Li, C., Bettati, R. \& Zhao, W. (1999). Adaptive connection admission control for mission critical real-time communication networks. Department of Computer Science, Texas A\&M University, College Station, TX 77843-3112.

Esaki, H., Iwamura, K., Kodama, T. \& Fukuda, T. (1994). Connection admission control in ATM networks. IEICE Transactions on Communications, E77-B(1), 15-27.

Goebel, G. (2003). An introduction to fuzzy control systems. Retrieved from http://www.faqs.org/docs/fuzzy/

Jiang, Y., Emstad, P. J., Nicola, V., \& Nevin, A. (2005). Measurement-based admission control: A revisit. Center for Quantifiable Quality of Service in Communication Systems, Department of Telematics, Norwegian University of Science \& Technology.

Kaehler. S. D. (1998, February 13). Fuzzy logic - An introduction: Part 1. ENCODER: The Newsletter of the Seattle Robotics Society.

Kennedy, C., \& Hamilton, K. (2006). Asynchronous transfer mode (ATM) switching. Cisco Systems Inc. October 12, 2006.

Kosko, B. (2003). Fuzzy thinking- the new science of fuzzy logic (1st ed.). NY: Hyperion Press. pp 18 - 34.

Suda, T. (1998). Asynchronous transfer mode (ATM) networks. University of California, Irvine, USA.

TechArena Community (2007). Asynchronous transfer mode (ATM) networks - Guide. Jelsoft Enterprises.

Tian, Y. (1998). A survey on connection admission control in ATM networks. Chicago, IL: DePaul University, School of Computer Science, Telecommunications and Information Systems.

Valcourt, S. A. (1997). Asynchronous transfer mode: An overview. ATM Consortium, June 24, 1997. 


\section{Biographies}

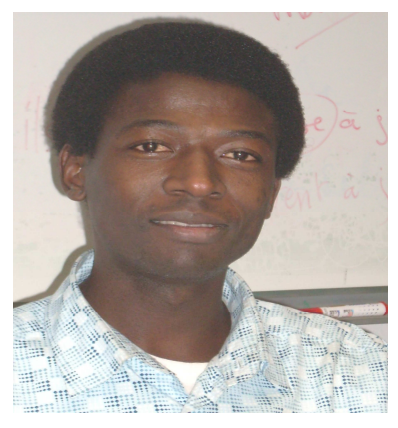

Olufade .F. W. Onifade is a lecturer in the Department of Computer Science, University of Ibadan, Oyo State, Nigeria. A recipient of the French Government Grant for the Doctoral co-supervised thesis (University of Ibadan \& Nancy 2 University, France). His research interests are in High Speed Networks, ATM Networks, Mobility Management in Mobile Ad hoc Networks, Video Streaming and Applications of Fuzzy Logic in system design and cognitive processes. He has published articles in International Journals of repute. Presently, his research is on Risk determination and management in Economic Intelligent processes towards strategic decision making.

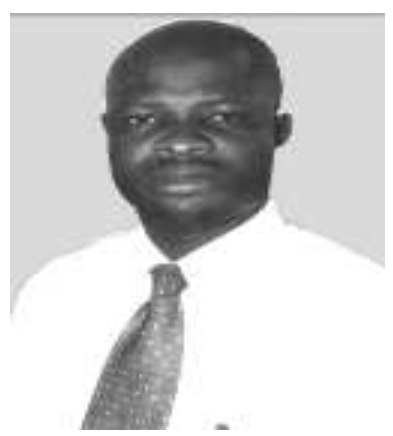

G.A. Aderounmu holds a research degree M.Sc./PhD in Computer Science from Obafemi Awolowo University, Ile-Ife, Nigeria (1997 and 2001, respectively). He is a member of the Nigerian Society of Engineers (NSE) and is also a registered computer engineer with Council for the Regulation of Engineering Practice in Nigeria (COREN). He is also a Member of Nigerian Computer Society (NCS) and Computer Professional Registration Council of Nigeria (CPN). He has over 13 years of experience in teaching and research. He is an author of many journal articles in Nigeria and abroad. His special interests include engineering education in Nigeria, curriculum development, and computer communication and network. He is a Visiting Research Fellow to the University of Zululand, Republic of South Africa. He is currently a Senior Lecturer, Deputy Director of the Information Technology and Communication Unit (INTECU) and the Acting Head of the Department of Computer Science and Engineering of the same university.

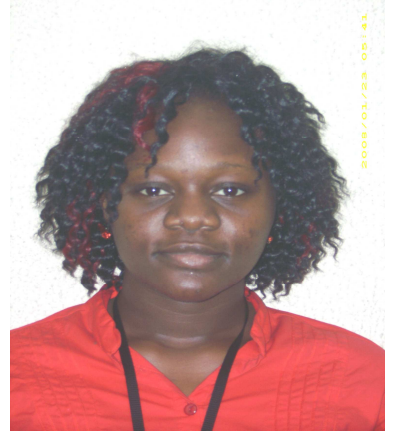

Oluwasikemi Tayo is a graduate of Bowen University, Iwo, Osun State from the department of Computer Science \& Information Technology. She is presently a team member of the Application development group of Interswitch Ltd. Her research area includes high speed networks traffic resolution, design and implementation of real time systems. 